\title{
Evaluation of the level of fear of radiation among radiology staff in hospitals affiliated to Hamadan University of Medical Sciences, Iran, in 2014
}

\author{
Ghazikhanlu-Sani K, $\mathrm{PhD}^{1}$, Alizadeh M, MSc${ }^{2 *}$, Mohammadi F, BSc ${ }^{3}$, Mohamadpour S, \\ $\mathrm{BSc}^{3}$, Hadidi Sh, $\mathrm{BSc}^{3}$, Mohammadi $\mathrm{Y}, \mathrm{PhD}^{4}$ \\ 1- Assistant Prof., Dept. of Radiology, Faculty of Para Medicine, Hamadan University of Medical Sciences, Hamadan, Iran. \\ 2- MSc in Medical physics, Dept. of Radiology, Faculty of Para Medicine, Hamadan University of Medical Sciences, \\ Hamadan, Iran. 3- BSc in Radiology, Dept. of Radiology, Hamedan University of Medical Sciences, Hamadan, Iran. 4- \\ Assistant Prof, Dept of Biostatistics \& Epidemiology, School of Public Health, Hamadan University of Medical Sciences, \\ Hamadan, Iran.
}

Received: August 2016, Accepted: December 2016

Background: The biological effects of radiation on radiology personnel are divided into two groups of deterministic effects and stochastic effects. Due to the effects of radiation on health, radiology staff may be afraid of radiation. Younger personnel with little work experience, compared with older personnel, have higher level of fear. The fear among radiology personnel, like employees of various departments, can impact their job satisfaction and performance.

Materials and Methods: This descriptive, cross-sectional research was performed on radiology staff of hospitals affiliated with Hamadan University of Medical Sciences, Iran, in the year 2014. In total, 70 questionnaires were distributed among the radiology personnel of these hospitals, of which 49 questionnaires were completed. This questionnaire consisting of 14 questions scored on a 5-point Likert scale ranging from 1-5 (from very high to very low). All P-values of more than 0.05 (P > 0.05) were considered significant.

Results: No significant relationship was observed between fear of radiation and education, age, gender, marital status, and work experience.

Conclusions: The total mean for very low level of fear of radiation among the radiology staff of hospitals affiliated to Hamadan University of Medical Sciences was 15.73\%. Furthermore, no significant relationship was observed between fear and other variables such as education, age, gender, marital status, and work experience $(\mathrm{P}>0.05)$.

Keywords: Radiology, Radiation, Fear

\section{Introduction}

Approximately 30 million workers are professionally exposed to radiation, and of these workers, interventional fluoroscopists (cardiologists and radiologists) are amongst the most exposed. In fact, their annual exposure is equivalent to $5 \mathrm{mSv}$ per year which would lead to a projected lifetime attributable excess cancer risk of 1 in 100 (1). Due to their penetrating ability, hard X-rays are widely used for imaging the inside of objects, e.g., in medical radiography (2). The radiation doses involved in radiology procedures other than interventional procedures are seldom sufficiently large to have deterministic effects (3). By definition, a deterministic effect has a practical threshold in dose, the severity of the effect increases with dose, and it results from damage to many

\footnotetext{
* Corresponding author: Majid Alizadeh, Dept. of Radiology, Faculty of Para Medicine, Hamadan University of Medical Sciences, Hamadan, Iran. E-mail: Alizadeh_majid@ymail.com
} 
cells. Stochastic effects are those that occur by chance and consist primarily of cancer and genetic effects. Stochastic effects are often revealed years after exposure. The probability of the occurrence of cancer or a genetic effect increases with increase in individual dose (4). However, at no time, even for high doses, is it certain that cancer or genetic damage will be the outcome. Similarly, for stochastic effects, there is no threshold dose below which it is relatively certain that an adverse effect cannot occur. In addition, because stochastic effects can occur in individuals that have not been exposed to radiation above background levels, it can never be determined for certain that an occurrence of cancer or genetic damage was due to a specific exposure $(2,4)$.

Due to the effects of radiation on health, radiology workers may be afraid of radiation. This fear of radiation can be illogical or positive; illogical fear is fear of radiation that interferes with routine performance. The radiation worker overtaken by this kind of fear may be aware that it is illogical fear, but at the same time be unable to overcome it. On the other hand, positive fear of radiation is due to lack of knowledge and disregard for safety measures $(5,6)$. In addition, the personnel working in other hospital departments have perhaps experienced fear or stress related to their occupation $(7,8)$.

One of the most important effective factors on decreasing radiology personnel's fear of radiation can be awareness of its damages (5). Since 1928, the International System of Radiological Protection (ICRP) has developed, maintained, and elaborated the ICRP used worldwide as the common basis for radiological protection standards, legislation, guidelines, programs, and practice. The ICRP offers its recommendations to regulatory and advisory agencies, and provides advice intended to be of help to the management and professional staff with responsibilities for radiological protection $(2,3)$.

The results of the most recent studies have shown that following the radiological protection standards has caused a decrease in mortality due to cancer among radiology personnel (2).

The fear among radiology personnel as well as the personnel of different departments can affect their function and job satisfaction; radiology assistants, due to fear or stress, may not be able to perform portable radiology or may not have motivation to work for additional hours $(9,10)$. Radiology personnel generally work with radiology instruments in different hospital departments, and the fear of radiation may affect their function. Other hazards of working with radiation have been studied in recent years $(1,9)$. Young personnel with little work experience, in comparison with older personnel, may have higher level of radiation fear. The present study was undertaken with the aim to evaluate the level of radiation fear among radiology personnel in order to offer ways for overcoming fear and stress.

\section{Material and Methods}

The present cross-sectional research was conducted among radiology personnel in hospitals affiliated with Hamadan University of Medical Sciences, Iran, in the year 2014. The statistical population consisted of all radiology personnel of 5 hospitals in Hamadan.

A questionnaire was designed by the researchers in order to collect data. The validity of the questionnaire was verified by 4 professors of the Department of Radiology of Hamadan University of Medical Sciences. The reliability coefficient of the questionnaire was evaluated using Cronbach's alpha ( $\alpha=0.938)$.

The number of 70 questionnaires was distributed in 3 different shifts at the hospitals. The questionnaires were collected after 2 weeks. In total, 49 questionnaires were completed and returned by personnel. The questionnaire consisted of 14 multiple choice items scored on a 5-point Likert scale ranging from 1-5 (very low to very high). The questions were related to personnel's feelings during working with a fixed radiography 
system and portable radiography system, tendency toward working an extra shift, and radiation protection. Their fear of radiation was investigated indirectly in these questions. The obtained data were analyzed in SPSS software (version 16, SPSS Inc., Chicago, IL, USA).

Chi-square and Fisher's exact tests were used to determine fear. Moreover, variables such as gender, age, education, marital status, and work experience were also considered. The fear of radiation was expressed as a percentage. Furthermore, scores of 14 to 42 indicated low level of fear, 42 to 70 indicated high level of fear, and 42 was considered as the average.

\section{Results}

The demographic characteristics of personnel are presented in table 1 . As can be seen, 49 personnel were studied, $52 \%$ and $48 \%$ of whom were, respectively, over 30 years of age and below 30 years of age. In terms of marital status, $66 \%$ of the personnel were married and $34 \%$ of them were single. Furthermore, $68 \%$ of personnel were men and $32 \%$ of them were women. In terms of education level, $71 \%$ of personnel had a bachelor's degree, $27 \%$ had an associate degree, and $2 \%$ had a Master of Science degree. Moreover, $57 \%$ of total personnel had less than 10 years of work experience and $43 \%$ had more than 10 years of work experience.

Table 1: The demographic characteristics of personnel

\begin{tabular}{|c|c|c|c|c|c|c|c|c|c|c|c|}
\hline & \multicolumn{2}{|c|}{$\begin{array}{c}\text { Work } \\
\text { experience }\end{array}$} & \multicolumn{3}{|c|}{ Educational degree } & \multicolumn{2}{|c|}{ Gender } & \multicolumn{2}{|c|}{ Marital status } & \multicolumn{2}{|c|}{ Age (year) } \\
\hline & $\begin{array}{c}\text { Over } \\
10 \\
\text { years } \\
\end{array}$ & $\begin{array}{l}\text { Under } \\
10 \text { years }\end{array}$ & $\begin{array}{c}\text { Master of } \\
\text { Science } \\
\text { degree }\end{array}$ & $\begin{array}{c}\text { Bachelor's } \\
\text { degree }\end{array}$ & $\begin{array}{l}\text { Associate } \\
\text { degree }\end{array}$ & Male & Female & Single & Married & $21-30$ & $31-53$ \\
\hline Number & 21 & 28 & 1 & 35 & 13 & 16 & 33 & 17 & 32 & 24 & 25 \\
\hline Percentage & 43 & 57 & 2 & 71 & 27 & 32 & 68 & 34 & 66 & 48 & 52 \\
\hline
\end{tabular}

The relation among variables and personnel's level of fear are presented in table 2. For the assessment of the relation between variables, the chi-square statistical test was used. According to this test, level of fear had no significant association with variables such as gender, age, education, marital status, and work experience. All P-values of more than $0.05 \quad(\mathrm{P}$-value $>0.05) \quad$ were considered significant.

Table 2: Relation among variables and personnel's level of fear

\begin{tabular}{|c|c|c|c|c|c|}
\hline Variable & & Low & High & Total & P-value \\
\hline \multirow{4}{*}{$\begin{array}{c}\text { Educational } \\
\text { degree }\end{array}$} & Associate degree & 11 & 2 & 13 & \multirow{3}{*}{0.364} \\
\hline & Bachelor's degree & 28 & 7 & 35 & \\
\hline & Master of Science degree & 1 & 0 & 1 & \\
\hline & Total & 40 & 9 & 49 & \\
\hline \multirow{3}{*}{ Age (year) } & $21-30$ & 18 & 6 & 24 & \multirow{2}{*}{0.24} \\
\hline & $31-53$ & 22 & 3 & 45 & \\
\hline & Total & 40 & 9 & 9 & \\
\hline \multirow{3}{*}{ Gender } & Male & 12 & 4 & 16 & \multirow[t]{2}{*}{0.697} \\
\hline & Female & 28 & 5 & 33 & \\
\hline & Total & 40 & 9 & 49 & \\
\hline \multirow{3}{*}{$\begin{array}{l}\text { Marital } \\
\text { status }\end{array}$} & Married & 14 & 3 & 17 & \multirow{2}{*}{0.924} \\
\hline & Single & 26 & 6 & 32 & \\
\hline & Total & 40 & 9 & 49 & \\
\hline \multirow{3}{*}{$\begin{array}{c}\text { Work } \\
\text { experience }\end{array}$} & Under 10 years & 21 & 7 & 28 & \multirow{2}{*}{0.166} \\
\hline & Over 10 years & 19 & 2 & 21 & \\
\hline & Total & 40 & 9 & 49 & \\
\hline
\end{tabular}


Statistical indicators related to the score of fear for each variable are presented in table 3 . The analyzed data showed that the level of fear of radiation was low among $81.6 \%$ of personnel and the level of fear of radiation was high among $18.4 \%$ of personnel.

Table 3: Statistical indicators related to the score of fear for each variable

\begin{tabular}{|c|c|c|c|c|}
\hline Variables & & Mean & Standard deviation & $\mathbf{P}$ \\
\hline \multirow{3}{*}{$\begin{array}{c}\text { Educational } \\
\text { degree }\end{array}$} & Associate degree & 38.15 & 4.61 & \multirow{3}{*}{0.89} \\
\hline & Bachelor's degree & 38.60 & 5.87 & \\
\hline & Master of Science degree & 37 & 0 & \\
\hline \multirow{2}{*}{ Age (year) } & $21-30$ & 38.45 & 5.50 & \multirow{2}{*}{0.63} \\
\hline & $31-53$ & 38.12 & 5.75 & \\
\hline \multirow{2}{*}{ Gender } & Male & 38.75 & 7.01 & \multirow{2}{*}{0.77} \\
\hline & Female & 38.30 & 4.64 & \\
\hline \multirow{2}{*}{ Marital status } & Married & 38.58 & 5.45 & \multirow{2}{*}{0.89} \\
\hline & Single & 38.37 & 5.55 & \\
\hline \multirow{2}{*}{$\begin{array}{c}\text { Work } \\
\text { experience }\end{array}$} & Under 10 years & 38.82 & 5.86 & \multirow{2}{*}{0.46} \\
\hline & Over 10 years & 37.95 & 4.97 & \\
\hline
\end{tabular}

\section{Discussion}

Johson conducted a study on public fear of radiation in 2011 (11). Although radiation is deadly in very specific circumstances, there is public fear of radiation because of the existing myths about radiation; thus, this fear can be decreased by enhancement of the level of knowledge (11). As an example, the Chernobyl incident in recent years has caused a public fear of radiation (12).

Gheledof et al., in their study about fear of working in proximity to radiation, concluded that the difficult working conditions have caused fear of radiation (13).

Pastel et al. investigated the fear of radiation among the U.S. military medical personnel (14). The questionnaires were completed by the personnel before and after 3 days of education on radiation. The results showed a positive correlation between increasing knowledge on radiation and more positive attitudes (14). Another study on fear of radiation during work with portable radiography was performed by Grazer et al. (15). Their results indicated that standing at an appropriate distance, using an apron, and taking care of the patient can decrease radiation dose (15). Balter studied fluoroscopic personal radiation protection equipment, and showed that unwarranted radiation fears should not drive the radiation protection system to the point of decreasing overall safety (16). The study by Shakerian et al. on radiation fear in Royal Melbourne Hospital, Australia, showed that concerns regarding fetal radiation have resulted in a low rate of compliance with recommended trauma guidelines in their institution (17). The fear of radiation in treatment with iodine-131 may be successfully managed by rational, authoritative, and empathic explanation on the definition of the risk, and gain patients' willing acceptance within the context of domiciliary patient care (18).

\section{Conclusion}

The radiology personnel work with X-ray equipment continuously, and fear may have negative effects on their function. A large number of personnel dislike performing portable radiography; this may be due to their fear of radiation. Younger personnel with little work experience, in comparison with older personnel, showed higher level of fear. The results show that increase in staff's awareness regarding radiation can reduce fear of radiation. In addition, courses on radiation protection can be useful for personnel. Based on the findings of this research, it can be concluded that the mean very low and low 
level of fear of radiation among radiology personnel in hospitals in Hamadan was $15.73 \%$ and $16.58 \%$, respectively. Moreover, fear had no significant relationship with other variables such as gender, age, education, marital status, and work experience. Therefore, the findings in this research show that further research is necessary on this topic $(\mathrm{P}>0.05)$.

\section{Acknowledgements}

The authors would like to thank Hamadan University of Medical Sciences for funding this work, and the personnel of the radiology department of hospitals in Hamadan for their kind assistance in completing the questionnaires.

Conflict of interest: None declared

\section{References}

1. Marazziti D, Baroni S, Lombardi A, Falaschi V, Silvestri S, Piccinni A, federico Mucci, Liliana dell'osso, et al. Psychiatric effects of ionizing radiation. Clin Neuropsychiatry 2014; 11(2):617.

2. Hall EJ, Giaccia AJ. Radiobiology for the Radiologist. Philadelphia, United States: Lippincott Williams \& Wilkins; 2006.

3. Armstrong IS, Saint KJ, Tonge CM, Arumugam P. Evaluation of general-purpose collimators against high-resolution collimators with resolution recovery with a view to reducing radiation dose in myocardial perfusion SPECT: A preliminary phantom study. J Nucl Cardiol 2016; 23(149):1-9.

4. Statkiewicz-Sherer MA, Visconti PJ, Ritenour ER, Haynes K. Radiation protection in medical radiography. 7th ed. Missouri, United States: Mosby; 2013. 392.

5. Quimby EH. The fear of radiation. Am Assoc Ind Nurses J 1967; 15(3): 19.

6. Katayama H. Relationship between emotional labor and job-related stress among hospital nurses. Nihon Eiseigaku Zasshi 2010; 65(4):5249.

7. Suresh P, Matthews A, Coyne I. Stress and stressors in the clinical environment: a comparative study of fourth-year student nurses and newly qualified general nurses in Ireland. J Clin Nurs 2013; 22(5-6):770-9.

8. Xie Z, Wang A, Chen B. Nurse burnout and its association with occupational stress in a crosssectional study in Shanghai. J Adv Nurs 2011; 67(7):1537-46.

9. Vanhoudt N, Vandenhove H, Real A, Bradshaw C, Stark K, et al. A review of multiple stressor studies that include ionizing radiation. Environ Pollut 2012; 168:177-92.

10. Davidhizar R, Dowd S, Giger J. Managing a multicultural radiology staff. Radiol Manage 1997; 19(1):50-5.

11. Johnson R. Psychological and mental health aspects of ionizing radiation exposure. Amsterdam, London: Elsevier; 2015.

12. Donna Coates T. Public relations and the radiation processing industry. Radiat Phys Chem 1990; 35(1-3): 354-6.

13. Gheldof EL, Vinck J, Vlaeyen JW, Hidding A, Crombez G. The differential role of pain, work characteristics and pain related fear in explaining back pain and sick level in occupational settings. Pain 2005; 113(1-2):71-81.

14. Pastel RH, Mulvaney J. Fear of radiation in U.S. military medical personnel. Mil Med 2001; 66(2):80-2.

15. Grazer RE, Meislin HW, Westerman BR, Criss EA. Exposure to ionizing radiation in the emergency department from commonly performed portable radiographs. Ann Emerg Med 1987; 16(4):417-20.

16. Balter S. Promoting fluoroscopic personal radiation protection equipment: unfamiliarity, facts and fears. Radiat Prot Dosimetry 2016; 172(1-3):181-6.

17. Shakerian R, Thomson BN, Judson R, Skandarajah AR. Radiation fear: Impact on compliance with trauma imaging guidelines in the pregnant patient. J Trauma Acute Care Surg 2015; 78(1):88-93.

18. Calais PJ, Page AC, Turner JH. Management of fear of radiation exposure in carers of outpatients treated with iodine-131. Ann Nucl Med 2012; 26(6):508-14. 